INVESTIGACIÓN/RESEARCH

\title{
COMUNICACIÓN POSITIVA: LA COMUNICACIÓN ORGANIZACIONAL AL SERVICIO DE LA FELICIDAD
}

José Antonio Muñiz-Velázquez: Universidad Loyola Andalucía. España. jamuniz@uloyola.es

Alejandro Álvarez-Nobell: Universidad San Jorge (Zaragoza). España. aalvarez@usj.es

\section{RESUMEN}

La Comunicación Positiva se quiere presentar como un paradigma importado de los planteamientos de la reciente Psicología Positiva, subdisciplina inaugurada principalmente por Martin E. P. Seligman, la cual podría definirse como aquella rama de la psicología que tiene como objeto de estudio la excelencia, el bienestar psicológico y subjetivo, la optimización de la vida y la felicidad del ser humano. En esa línea, el objetivo del presente trabajo es dar a conocer la senda que desde diferentes focos se está tomando hacia lo que llamaremos la comunicación positiva, que podríamos definir como aquella comunicación organizacional que, al margen de otros objetivos, fomenta consciente o inconscientemente la felicidad y el bienestar psicológico de los públicos a los que se dirija. Si bien las posibilidades de confluencia entre felicidad humana y comunicación aún están en un estado incipiente, parece haber por delante un enorme y prometedor terreno por explorar.

PALABRAS CLAVE: Comunicación positiva - Publicidad positiva - Responsabilidad Social Empresarial (RSE) - Felicidad - Bienestar psicológico.

\section{POSITIVE COMMUNICATION: ORGANIZATIONAL}

\footnotetext{
${ }^{1}$ Autor correspondiente:

José Antonio Muñiz-Velázquez: Profesor ayudante e investigador en la Facultad de Ciencias Sociales, Jurídicas y de la Educación, de la Universidad Loyola Andalucía, en el Grado de Comunicación.

Correo: jamuniz@uloyola.es
} 


\title{
COMMUNICATION SERVING HAPPINESS
}

\begin{abstract}
Positive communication is being presented as a paradigm approaches imported from the recent positive psychology subdiscipline mainly inaugurated by Martin E. P. Seligman, which could be defined as that branch of psychology that aims to study the excellence, the psychological and subjective optimization of life and human happiness. In this regard, the objective of this work is to show the path toward what we call positive communication, which could be defined as the organizational communication that, regardless of other goals, promotes consciously or unconsciously the happiness and psychological well-being of the individuals. While the chances of confluence between human happiness and communication are still in a nascent state, there is a huge and promising field ahead to explore.
\end{abstract}

KEY WORDS: Positive communication - Positive advertising - Corporate Social Responsibility (CSR) - Happiness - Psychological well-being.

\section{INTRODUCCIÓN}

Desde que se funda la psicología como ciencia de pleno derecho, con el comportamiento humano como objeto de estudio principal, siempre se centró mayoritariamente en las disfunciones del mismo, en los trastornos o problemas que a lo largo de la vida de las personas podrían abordarle. De tal suerte que al hablar de psicología y de psicopatología, si bien nunca aparecían como sinónimos, sí semejaban términos de una enorme concomitancia (Padrós et al., 2010). Pero a partir de 1998, con el trabajo principalmente de Seligman, surge lo que algunos clasifican como una subdisciplina, una psicología centrada en lo positivo del ser humano, en encontrar el camino para el florecimiento del bienestar psicológico y la felicidad de los individuos. De ese modo, se recogería, con algunos años de retardo, lo que postulara la Organización Mundial de la Salud en 1948, al definir salud como un estado completo de bienestar físico, mental y social, y no solamente la ausencia de enfermedad. En definitiva, de lo que se trata no es de estudiar las disfunciones, sino la felicidad y plenitud del ser humano, observar a las personas que aseguran ser felices y saber cómo lo logran, qué factores están conformando ese bienestar, y poder así hacer crecer a los demás, o en palabras de Sheldon y King (2001), se trata del "estudio científico de las fuerzas y virtudes humanas naturales, de una disciplina que se pregunta cuál es la naturaleza de la eficacia del funcionamiento del ser humano, centrando la atención en las potencialidades, los motivos y capacidades de éste". Más resumidamente, se trata de una nueva rama que se ocupa principalmente del estudio científico de las fuerzas y de la felicidad del ser humano (Carr, 2007).

Obviamente, toda esta corriente no surge espontáneamente de la nada. Ya se encuentran trabajos precedentes de psicólogos como Maslow, con su concepto de autorrealización, Rogers hablando de realización plena, o Allport con sus estudios sobre la madurez psicológica. Pero realmente hasta los trabajos de psicólogos como 
Seligman, Peterson, Csikszentmihalyi, Diener, etc., en las postrimerías del siglo XX, no toma el auge que podemos observar hoy día. Un auge que está impregnando poco a poco todos los ámbitos tanto científicos como de actuación e intervención de la psicología tradicional, si bien podríamos dividir su capacidad de influencia en tres grandes esferas de trabajo.

En primer lugar, nos encontramos con el estudio de la persona positiva, del individuo con una personalidad y una configuración de rasgos positiva, con trabajos como los de Csikszentmihalyi a la cabeza. En segundo lugar, como otro gran marco de actuación, la psicología positiva gira alrededor de las emociones positivas, de la configuración emocional que hace crecer y florecer una vida interior satisfactoria, con Diener a la cabeza. Y como tercer gran ámbito de actuación, nos encontramos con el plano psicosocial, con una psicología social positiva pivotando alrededor de las instituciones y organizaciones calificadas como positivas. Con ello, también la psicología social, que compartía con la psicología clínica tradicional el enfoque en lo negativo, vira también hacia el signo positivo. Se centrará, por tanto, en los aspectos psicosociales que permiten que las comunidades y grupos humanos prosperen y mejoren en el desarrollo de las fortalezas y virtudes de las personas. Y todo ello tanto desde el plano organizacional y empresarial como institucional y sociológico. En este último sentido, se considerarían también instituciones positivas cosas como, por ejemplo, la Democracia, la Libertad de Información, la Educación, etc.

Pues bien, será en el ámbito de lo organizacional y psicosocial donde de una manera más preeminente entronque el postulado de una comunicación positiva que venimos a defender, una comunicación positiva en el seno de empresas y organizaciones que se pone al servicio de la felicidad humana.

\section{DESARROLLO}

\section{1 ¿Pero qué sabemos de la felicidad humana?}

No son pocas las disciplinas y los saberes que se han aproximado al constructo de felicidad a lo largo de los tiempos, desde Aristóteles hasta nuestros días. Al ser ciertamente algo tremendamente poliédrico, podemos encontrar acercamientos y planteamientos dispares y heterogéneos. Ahora bien, en el fondo todos ellos podrían agruparse en dos grandes tendencias, una conocida como la hedónica y otra como la eudaimónica (Ryan y Deci, 2001). Por un lado están las concepciones de felicidad congregadas en torno al constructo de bienestar subjetivo, al grado en que las personas se sienten y autoidentifican como satisfechas con su vida. En palabras de Diener, al hecho de "haber experimentado frecuentemente y de forma prolongada un tono de ánimo positivo, y con poca frecuencia y duración estados de ánimo negativo" (citado en Avia y Vázquez, 2011: 43).

Partiendo también, en un principio, de esa misma concepción hedónica, Sonja Lyubomirsky definirá felicidad como aquella "experiencia de alegría, de satisfacción y bienestar a raíz principalmente del sentimiento y la concepción de la vida de la propia persona como algo con sentido, con plenitud y que merece la pena ser vivida" (2011, p. 58), si bien vemos que lleva el asunto a un terreno ligeramente más allá de lo 
hedónico. Frente a esa hedonia, la aristotélica eudaimonia asocia felicidad a un bienestar psicológico surgido de vivir con arreglo a un ideal de perfección humana, esto es, a la virtud. En ese sentido, la "felicidad auténtica" se obtendría "con el ejercicio de las propias capacidades y fortalezas encaminadas a un desarrollo psicológico óptimo" (Avia y Vázquez, 2011, p. 46), y no con un mero bienestar surgido de situaciones sensorial o psicológicamente placenteras. Al mismo tiempo, cabe señalar que esta perspectiva no excluye que en esa visión eudaimónica no quede integrada una buena dosis de hedonia, esto es, que también en la práctica de la virtud cabe contemplar bienestar subjetivo, sensaciones placenteras, emociones positivas, etc. Por tanto, podría entenderse que más bien estemos hablando, en lugar de dos caminos distintos de aproximación a la felicidad humana, de uno solo, si bien dividido en dos etapas, una primera o básica, la hedónica, y una segunda y más profunda o auténtica, la eudaimónica.

Es en esta segunda concepción eudaimónica donde cada vez se está encontrando más respaldo científico con el que perfilar la naturaleza de la felicidad propiamente humana, como pone de relieve, entre otros muchos, el largo trabajo que vienen desarrollando Peterson y Seligman (2004), quienes ha aportado una sesuda taxonomía de virtudes y fortalezas psicológicas del Ser Humano conducentes a esa felicidad auténticamente humana (véase anexo). Son, en su conjunto, los puntales que según estos autores sustentan la felicidad, o en palabras del reciente Seligman (2011), el bienestar humano, y que al margen de posibles debilidades epistemológicas que pudieran presentar, como pone de manifiesto Gancedo (2006), lo cierto es que son múltiples los estudios e investigaciones que encuentran correlación, y relación causal incluso, entre muchas de estas fortalezas y el bienestar psicológico o la felicidad de los individuos.

Pues bien, es a través de ese conjunto de fortalezas donde entra de lleno la comunicación como algo estrechamente relacionado con la felicidad. El hecho es que muchas de esas fortalezas y virtudes no pueden pasar sin la comunicación para existir y desarrollarse, una comunicación que iría del plano interpersonal al organizacional. Incluso cabe llegar más lejos en esa aproximación de ambos constructos. Por ejemplo, Mithen (2006), entre otros muchos paleontólogos y etólogos, declaran que si la felicidad es una de las claves de la evolución de la especie humana, lo es a través del mecanismo tal vez más poderoso para ello, la cooperación entre los individuos, algo que necesita, sí o sí, comunicación. Es decir, la gente más feliz tiende a cooperar más, y viceversa, alcanzando así unos resultados inigualables con la mera suma las individualidades. Por tanto, si la cooperación sin la comunicación sería inviable, como vemos, la felicidad sin éstas también. Pero al margen de este punto, que da para mucho y excede el objeto del presente trabajo, otros muchos son los aspectos que a nuestro modo de ver conforman la relación entre felicidad y comunicación, una relación de la que surgirá la comunicación positiva.

\section{2 ¿Una comunicación positiva?}

En música se suele usar el término "transposición", concepto que aunque también se ha usado en pedagogía, procede de la música, y que describe el hecho de interpretar, o 
escribir, una obra musical en una altura o tesitura diferente, más aguda o más grave, a la que originariamente le diera el autor. En definitiva es llevar una música determinada a terrenos sonoros diferentes, y sin que cambie en esencia. Mutatis mutandis, esa sería la propuesta de trabajo que trata de recoger y describir esta exposición. Es decir, se pretende "transportar" el enfoque de la psicología positiva al terreno de la comunicación, y en particular de la comunicación social y organizacional, de la publicidad y las relaciones públicas, de hacer posible que desde el terreno de la comunicación humana se pueda leer e interpretar la "partitura" que viene escribiendo esta psicología del crecimiento humano.

Como acabamos de señalar más arriba, creemos además que un terreno y otro no están alejados. Es decir, al hablar de felicidad y de comunicación no es hacerlo de dos cosas tan alejadas. ¿Y si en el fondo la felicidad no es otra cosa que comunicación? Parece que la felicidad requiere de un proceso de comunicación intrasujeto, de diálogo interior, como apunta Lyubomirsky (2011), a través del cual la persona se sepa y se convenza o persuada a sí misma de que es feliz. Ese diálogo interior es el mismo que se estimula, por cierto, en algunas prácticas terapéuticas, como es el caso del disputing (Seligman, 2004), que consiste en disputar pensamientos pesimistas como si los hubiera dicho otro.

En esta línea coincidiría el neurofisiólogo Mora (2012), quien pone de manifiesto que la felicidad no deja de ser un constructo mental de sentimiento y pensamiento, y que para existir "precisa de un lenguaje y unos niveles de pensamiento y sentimientos bastante sofisticados, y requiere de un cerebro con niveles de conciencia que solo se alcanzan en escenarios de interacción social alta, de comunicación fluida" (Mora, 2012, p. 38). Parece, por tanto, que la felicidad necesitaría ineludiblemente de comunicación para existir. Y si necesita de la comunicación, necesita de la persuasión, de una persuasión positiva, porque toda comunicación lleva algo de persuasión, o lo que es lo mismo, comunicar es influir, como sostuviera Watzlawick (1993), aunque esto será otro de los aspectos que habremos de dejar para más adelante.

Llegados a este punto, cabe ofrecer una definición de lo que llamaremos comunicación positiva, y diremos que podrá considerarse como tal aquella comunicación humana, sea en el ámbito interpersonal o en el organizacional, institucional o empresarial, que va encaminada a mejorar el grado de bienestar psicológico o felicidad eudaimónica del conjunto de receptores, independientemente de si dicha comunicación alberga objetivos de otra índole, sean éstos eminentemente persuasivos, informativos, o de entretenimiento. Cierto es que algo parecido en el plano psicológico, médico y de la salud se viene trabajando desde hace tiempo. También en el plano de las organizaciones, la psicología social y organizacional lleva cierto camino recorrido. Es por esa vía por donde va introduciéndose en el terreno de la comunicación interna, aunque tímidamente. Donde parece que puede causar mayor revuelo es en el terreno de la comunicación externa, de la publicidad, de las relaciones públicas y de la Responsabilidad Social Corporativa. Veamos todo ello por partes.

\subsection{Felicidad y comunicación interna}


Lo cierto es que el bienestar y la felicidad en el ámbito del trabajo y la empresa es un tópico que va dejando de ser incipiente, al ir tomando un considerable cuerpo científico (Fisher, 2010). No en balde el estudio de la felicidad en el trabajo recoge la tradición investigadora alrededor de constructos como la satisfacción laboral, el compromiso afectivo organizacional, los estados de ánimo en el trabajo, etc. Por tanto, lo que podríamos llamar "felicidad organizacional", o "felicidad corporativa", no es un concepto que surja de la nada. Dicho concepto vendría definido grosso modo como aquel estado de bienestar psicológico que aparece de modo generalizado en el seno de una empresa $u$ organización, si bien, y debido al enfoque eudaimónico antes planteado, deberá ser forzosamente algo más que la suma de las "felicidades" individuales de sus miembros.

Una empresa eudaimónicamente feliz será, por tanto, aquella que cuente con miembros mayoritariamente felices, pero felices eudaimónicamente hablando, al mismo tiempo que deberá, como organización, comportarse eudaimónica y virtuosamente, tanto para con sus públicos internos como externos. Parece, asimismo, que solo así, una empresa alcanzará con mayores garantías un éxito duradero, fundamentado y estable, al margen de las veleidades momentáneas de las coyunturas económicas. Para afirmar esto, cada vez son más las evidencias científicas. Al igual que ocurre con las personas físicas, también para las personas jurídicas, esto es, las empresas, ser bueno con los demás correlaciona positivamente con la felicidad de quien lo practica (Post, 2005), y habrá que empezar por esos "demás" que pertenecen a la empresa.

La correcta gestión de y para la felicidad de los públicos internos, por tanto, se plantea como algo clave no ya para el éxito de una organización o empresa, sino para su mera supervivencia. En esa línea, Achor (2010) o Lyubomirsky, King y Diener (2005), entre otros, recopilan una numerosa serie de investigaciones en las que se constata que la felicidad interior es la causa de que tarde o temprano se alcance el éxito en la práctica totalidad de los terrenos de la vida, ya sea individual $u$ organizacionalmente hablando. Uno de los posibles mecanismos explicativos de que el afecto positivo genera éxito, podría ser el hecho de que las personas felices son más propensas a adquirir circunstancias vitales favorecedoras en mayor cuantía, al asociarse también de algún modo con una visión optimista de los acontecimientos (Avia y Vázquez, 2011).

Centrándonos en los públicos internos, de entre los factores con los que cuenta una empresa para causar felicidad o infelicidad a los mismos, parece que la principal fuente de felicidad es, por encima del salario y otros condicionantes materiales, el conjunto de relaciones positivas que nos encontramos en nuestro puesto de trabajo. Parece, por tanto, que también en el trabajo la felicidad son los demás, como dijera Seligman (2011). Y paralelamente a ello, la principal fuente de malestar o infelicidad en el entorno laboral es el padecer una mala relación con los compañeros (Chiumento, 2007).

Obviamente, relacionado a la calidad de esas relaciones aparece el tono comunicativo del que se disfrute, tanto vertical como horizontalmente hablando. Por tanto, una 
óptima comunicación interna de las organizaciones, a todos los niveles, parece crucial para esa gestión de la felicidad organizacional de la que venimos hablando. Felicidad y comunicación, también en el seno de la empresa, parecen consustanciales en buena medida. La apuesta pertinente parece apuntar, por tanto, a una gestión de la comunicación interna, tanto formal como informal, en la medida de lo posible, encaminada a fortalecer, además del compromiso y la identificación con la organización y sus valores, el desarrollo personal y el bienestar psicológico de las personas que la componen, objetivo último que al cumplirse se verán cumplidos otros objetivos empresariales y organizacionales importantes, a través de esa correlación causal empíricamente demostrada (Achor, 2010). Bajo esta perspectiva, lo que llamaremos comunicación interna positiva actuaría en diferentes ámbitos organizacionales, teniendo resultados en varios sentidos:

Comunicación interna y salud: En primer lugar, con la felicidad como meta de la comunicación interna es de esperar ver previsiblemente aumentado el nivel de salud general de la organización. Tradicionalmente se considera que la salud es causa de la felicidad. Sin embargo, cada vez son más las evidencias de que la relación sería más bien a la inversa, esto es, que la salud o la enfermedad pueden provocar indistintos estados de felicidad, pero que la felicidad puede ayudar o ser parte de la causa de tener una mejor salud. Cohen et al. (2003), por ejemplo, midieron los niveles de felicidad de una muestra de personas, y tras ello les inyectaron una cepa del virus del resfriado. Unos días más tarde, observaron que las personas más felices según sus mediciones enfermaron menos, presentando menos síntomas del resfriado (estornudos, tos, inflamación, congestión...) que los que se diagnosticaron como menos felices. De alguna manera, la felicidad nos protege de la enfermedad también biológicamente, al contrario que la infelicidad, que parece causar alteraciones en el sistema inmunológico (Avia y Vázquez, 2011).

Es fácil inferir las implicaciones que esto tiene para la empresa. No solo parece que los trabajadores felices serán más productivos y eficientes, sino que además enfermarán menos, provocando menos absentismo y por tanto menos costes para la empresa (Achor, 2010).

Comunicación interna para la resiliencia: En segundo lugar, la felicidad parece estar estrechamente relacionada con dos parámetros psicológicos que gozan ya de una considerable investigación, el optimismo y la resiliencia. Por un lado, el optimismo y la felicidad gozan de una enorme cercanía y correlación (Avia y Vázquez, 2011). Podríamos definir el optimismo como un estilo de pensamiento que generalizadamente atribuye resultados positivos a eventos actuales y futuros (Seligman, 2004), y si bien es cierto que tiene una fuerte carga hereditaria, también es cierto que es algo que se puede aprender y también ejercitar, como dejan patente Avia y Vázquez (2011), al igual que se debe aprender, y enseñar diríamos, que "la primera condición para ser más feliz es comprometerse con esa meta, recordarse a uno mismo y hacerse consciente de que vivir mejor y ser más feliz importa" (Avia y Vázquez, 2011, 285). Que importa y que es posible, cabría añadir. Por lo tanto, podría decirse que la propia felicidad parte de un proceso de comunicación autopersuasiva de uno mismo para con uno mismo que pasa necesariamente por el optimismo. 
Por otro lado, más allá del optimismo nos encontramos con la resiliencia, constructo que se relaciona con aquel proceso de afrontamiento que ayuda a la persona a mantenerse psicológicamente intacta ante los avatares de la vida (Carretero, 2010), si bien hay autores que llevan el concepto hasta contemplar en él también el posible crecimiento postraumático que a veces y en determinadas personas se da. Es decir, entendiéndola como la capacidad no solo de salir indemne de una experiencia adversa, sino de aprender de ella y mejorar (Carretero, 2010). Aprender a afrontar los obstáculos y problemas de la vida, y ser capaces de crecer a partir de ellos, es obvio que es algo bueno para los individuos, pero también para las organizaciones. No hace falta incidir más para ver claramente la importancia de todo ello en el escenario y la coyuntura económica actual, cuán importante es contar en una empresa con personas altamente resilientes para afrontar despidos de compañeros, por ejemplo, o merma de prebendas, derechos y prestaciones, y en general todo tipo de dificultades que se están dando en la actualidad. La comunicación interna positiva tiene aquí un terreno y unas posibilidades de trabajo enormes.

La "gestión de las vocaciones": En tercer lugar, la comunicación interna positiva debiera ocuparse también de velar por la maximización vocacional de las personas que integran la empresa u organización, algo que podría acercarse a lo que otros llaman gestión del talento (Robinson, 2009). Sabemos que una persona no será plenamente feliz en su trabajo sin que realmente le ponga vocación al mismo, sin que sienta que la actividad que lleva a cabo emana de lo más profundo de su interior y se alinea con sus intereses e inquietudes vitales. Por tanto, solo así conseguiría lo que Csikszentmihalyi (1996) llamara flow, o fluir, ese estado psicológico en el que la persona fluye en y con la tarea que está llevando a cabo en un momento determinado, a raíz de lo cual surge un estado de plenitud vital y psicológica que el autor identifica como felicidad. Si la persona, en el puesto que le está designado en la empresa, no es capaz de encontrar ese estado en al menos una parte considerable del tiempo que le dedica a la empresa, difícilmente será feliz, ni conseguirá el máximo potencial de sus capacidades, y por tanto, la excelencia. Desde la comunicación interna nos encontramos con excelentes herramientas para poder maximizar, en este sentido vocacional, y no solo curricular, la adecuación puesto-trabajador. En las medidas de las posibilidades, cuando esa adecuación no se dé, o bien se cambia al trabajador de puesto, o bien si no es factible, la vía habrá de venir por alinear internamente, que no alienar, al trabajador con su puesto de trabajo, tratar de despertar vocación en lo que le ha tocado hacer y desempeñar. Lo importante, en definitiva, es que la persona encuentre tanto un sentido a lo que hace como satisfacciones intrínsecas a la tarea suficientes como para experimentar ese bienestar psicológico ante lo encomendado, única manera de alcanzar un éxito duradero. Como afirman Avia y Vázquez, "el trabajo o las actividades cotidianas se convierten en una pesada carga, en una maldición bíblica, para quien no es capaz de encontrar algún sentido en ellas. La falta de significado, o no ser capaz de dotar de algún valor a lo que hacemos (...) crea una fuerte sensación de desconcierto, de aburrimiento o de vacío existencial." (2011, p. 286). Por el contrario, estos mismos autores afirman que "los momentos de felicidad no se asocian habitualmente a estados de simple relajo, sino más bien a una actividad mental o física en la que hemos puesto empeño" (Avia y Vázquez, 2011, p. 289). 
Paralelamente a ello, el ser capaces de centrarse en una tarea, en una misión externa a nosotros mismos, retroalimenta el propio estado de felicidad. Muchos trastornos psicopatológicos provienen de un exceso de atención en uno mismo, en los procesos de "autofoco", en palabras de Csikszentmihalyi (1996). Un buen antídoto es dedicarnos a alguna tarea que consideremos con sentido, superior a nuestra propia realidad de alguna manera. Como afirmara Russell "todo interés externo inspira alguna actividad que, mientras permanece activo, nos previene por completo del tedio. El interés por uno mismo, al contrario, no conduce a ninguna actividad progesiva." (1978, p. 31). Entre otras cosas, porque al mismo tiempo ese centrar el foco en la tarea se relaciona con la experiencia del "aquí" y el "ahora", con el hecho de mantener la conciencia y el estado atencional en el momento presente, algo que también articula el nivel de felicidad por el que vamos transitando los humanos, como defiende entre otros Tolle (2009).

Creatividad e Innovación: relacionado con lo anterior, es fácil deducir que las personas que sientan sus trabajo con mayores posibilidades creativas gozarán más de él, por norma general, en el sentido de que a priori les permitirá una relación más estrecha con el mismo, más fluida, menos monótona, etc., relacionándose así creatividad y felicidad. Dicha correlación la encuentran, por ejemplo, Dolan y Metcalfe (2012), si bien sin aclarar la causalidad. Otras investigaciones sí parecen avalar una causalidad entre ser feliz y por tanto más creativo (Stafford et al., 2010). Esto es, no es que un trabajo creativo nos reporte mayor felicidad, que también, sino que un estado interno de felicidad, de bienestar subjetivo, nos volverá más creativos e innovadores. Ante cualquier tipo de reto, Achor afirma que la felicidad "nos da una ventaja química a la hora de enfrentarnos a ese desafío" $(2010,62)$, puesto que las emociones positivas inyectan dopamina y serotonina, hormonas implicadas también en las funciones de aprendizaje del cerebro. Son las hormonas que ayudan a organizar la información nueva que se va recibiendo y a almacenarla mejor en la memoria. Esto será importante de cara a luego poder construir conexiones más interesantes y novedosas. Dicho autor, entre otros, no tendrá reparos en señalar a la felicidad como el verdadero motor de la innovación y la creatividad en el plano empresarial, algo que sin duda habrá de tener cada vez más en cuenta.

Comunicación, liderazgo y bienestar organizacional: Se parta del modelo de liderazgo que se parta, parece indiscutible el peso que en la comunicación interna y en el estado psicológico organizacional tiene la articulación de dicho liderazgo. Para empezar, la relación entre liderazgo y felicidad, y en concreto una felicidad fuertemente eudaimónica, parece cada vez más evidente. Para ser un líder en el pleno sentido de la palabra, parece necesario ser una persona feliz, virtuosa o eudaimónicamente feliz. Así por ejemplo, Hackett y Wang (2012), analizando el listado de virtudes que los diferentes modelos de liderazgo más comunes presentan, encontraron que todos ellos presentan coincidencias a la hora de señalar como claves las virtudes, ya señaladas por Aristóteles, de coraje, templanza, justicia y prudencia, y las ya apuntadas por Confucio, humanidad y honestidad, además de otras muchas. Todas ellas, como se podrá reparar, forman parte asimismo de las fortalezas humanas de Peterson y Seligman (2004) conducentes a la felicidad. Parece por tanto que el camino de llegada 
tanto a la felicidad como al liderazgo, es el mismo. Un líder auténtico habrá de pasar, necesariamente, por un considerable desarrollo personal, ser honesto y transparencia en las relaciones, actuar con equilibrio y ecuanimidad en las decisiones, con una moralidad internalizada, y un largo etcétera.

Para lograr un liderazgo fundamentado en las virtudes humanas, y por tanto, en la felicidad tanto del líder como de las personas que lo rodeen, el uso y diseño de la comunicación interna deberá responder forzosamente a los mismos principios, expuesto entre otros por Ulrich y Ulrich (2011), Greenleaf (1977), Barbuto y Wheeler (2006), Linden, Wayne, Zhao, \& Henderson (2008) o Van Dierendonck y Nuijten (2010): humildad, coherencia, desinterés, empatía, compromiso, y responsabilidad, apertura a la innovación, saber delegar, afrontar asertivamente todo tipo de situaciones, y funcionar como un nodo de conexión de un buen número de flujos, ya sean personales como de información, emocionales, y de toda índole. Por tanto, parece que la principal herramienta para todo ello que debiera manejar con total maestría un líder eudaimónico, debiera ser la comunicación positiva.

Por todo lo dicho, los líderes que ostentan puestos claves son los que más que nadie pueden y deben, "inundar su lugar de trabajo con una oleada de positividad" (Achor, 2010, p. 74), puesto que serán éstos en mayor medida los que modelarán la cultura organizacional, los que sirven de ejemplo para los comportamientos de otros, y porque son los que están más conectados y por tanto su capacidad de contagio es mayor. Porque en definitiva, si como afirma Sharma, "la empresa es un vehículo para ayudar a otros seres humanos" (2010, p. 184), el líder será su chófer.

\subsection{Felicidad y publicidad positiva}

Hablar de felicidad y publicidad, juntando ambos conceptos en una frase, no es nada novedoso, porque cierto es que la publicidad, desde sus inicios, lleva en los cimientos de su discurso una propuesta de venta implícita que siempre será la misma, la felicidad, una felicidad a través del consumo de los productos que publicita, siendo parte esencial de esa nueva "factoría de la felicidad" (Eguizábal, 2007, p. 174).

Otros señalarán que lo que realmente está relacionado con la publicidad no es la felicidad, sino la infelicidad humana. Algunos señalarán que, de hecho, lo que realmente vende la publicidad es infelicidad. Al mostrar con las mejores herramientas persuasivas posibles esa fuente continua de objetos deseables, lo que en el fondo está sembrando en los receptores es un sentimiento de carencia anexo al deseo, una insatisfacción particular en algo, y que a la larga puede ir asociada a otra más generalizada, a un descontento con la vida. La publicidad presenta un problema, una carencia, y luego ofrece la solución (el producto). En ese sentido, los estudios han relacionado más a la publicidad con el malestar y la infelicidad que con el bienestar, principalmente por la vía de la comparación social, como puso de manifiesto Richins (1995), o por la ansiedad generada por el estatus, deseado, tenido o perdido (Botton, 2004), o por otras vías, como por ejemplo a través del fomento del conflicto familiar y social (Buijzen y Valkenburg, 2003). 
Al margen de este punto, que da para una polémica mucho más amplia de lo que permiten estas páginas, lo que sí parece parece irremediable, al asociar publicidad y felicidad, es acordarnos de Coca-Cola y de toda la comunicación que desde hace un tiempo viene construyendo dicha marca, al menos dentro de nuestras fronteras. Pero ahora que sabemos un poco más sobre la felicidad humana, hay que señalar que lo que podríamos llamar publicidad positiva haría referencia a algo más que a aquellas campañas, o posicionamientos de marca, relacionados o centrados en el concepto o idea de la felicidad en sentido genérico, como el mencionado caso de Coca-Cola. En ese sentido, nos atreveremos a definir publicidad positiva como aquella publicidad (pieza, campaña o acción), que amén de cumplir con los objetivos de marketing y de comunicación para la que fue pergeñada, trata de instalar en los receptores ese estado de bienestar subjetivo y psicológico, en la línea de una felicidad no solo hedónica, sino también eudaimónica, comunicando valores en la órbita de las virtudes y fortalezas catalogadas por la psicología positiva. Es decir, aquella publicidad que además de vender lo que tenga que vender, persiga hacer crecer la felicidad auténtica del receptor fundamentada en la virtud.

En esa línea, varias son las iniciativas a las que habrá que atender, ya sea en el espacio propio de las marcas y empresas anunciantes, como de las agencias publicitarias. Ambos agentes del proceso publicitario están dando buena muestra de esto que venimos señalando. Cabe, por ejemplo, resaltar el planteamiento que el Grupo Bassat Ogilvy ha puesto encima de la mesa. Su propuesta es que la publicidad debe pasar de "la gran idea" al "gran ideal", o al The big ideaL ${ }^{T M}$, como dicen ellos mismos. Es decir, se trata de trabajar una comunicación que asocie la marca a un ideal, o dicho de otro modo, a alguno de los valores que la sociedad cada vez acoge con mayor fuerza. Por ejemplo, la agencia presenta el caso de la marca Dove, quien articulará su comunicación publicitaria en torno a decir que "Dove cree que el mundo sería mejor si las mujeres se sintieran bien consigo mismas". De alguna manera, se posicionan a las marcas como abanderadas en la lucha por un mundo mejor, donde impere un concepto de felicidad mucho más cercano a lo eudaimónico de lo que la felicidad hasta ahora vendida por la publicidad estaba, mucho más cercano no ya de lo hedónico, sino de lo meramente hedonista.

En cuanto a los anunciantes, cada vez son más las marcas que tratan de construir comunicación y posicionamiento ligadas a algún aspecto determinado de esa felicidad hedónica y eudaimónica de la que venimos hablando, como ponen de manifiesto, por ejemplo, Romero y Sánchez (2012), quienes analizaron el uso creciente, en el escenario actual de crisis, de valores de felicidad como recurso publicitario. Prácticamente ningún ámbito de consumo está quedando libre de contar con alguna marca o anunciante que vehicule su discurso publicitario sobre elementos que transmitan una felicidad sustentada en valores. Parece que precisamente la crisis también está obligando a la publicidad a buscar otro tipo de valores frente a los que hasta ahora, de manera tradicional y mayoritaria, revestía marcas y productos.

\subsection{Relaciones Públicas positivas}


También al terreno de las Relaciones Públicas cabría transponer el paradigma positivo del que venimos hablando. Bien es verdad que desde una perspectiva contemporánea y abierta, las relaciones públicas se deberían acercar de manera natural al planteamiento que defendemos. Si de algo existe una infinitud de definiciones, eso es las Relaciones Públicas, ahora bien, todas las que gozan de más o menos reconocimiento, vendrían a coincidir en algo básico, en que el objetivo de las Relaciones Públicas en palabras de Magallón no sería otro que el "establecimiento de vínculos plausibles y deseados entre la organización en cuestión y sus públicos específicos" (2006, p. 104), o como dicen Wilcox, Cameron y Xifra, "la construcción de relaciones mutuamente beneficiosas entre la organización y sus diversos públicos (...) en las que todas las partes ganan" (2006, p. 8).

Ahora bien, si hacemos caso a Long y Hazelton, cuando definen Relaciones Públicas como aquella "función directiva de comunicación a través de la cual las organizaciones se adaptan, alteran o mantienen su entorno con el propósito de lograr las metas de la organización" (citado en Wilcox, Cameron Xifra, 2006, p. 8), habrá que añadir que, para que sean consideraras Relaciones Públicas positivas, deberán encaminar esa alteración del entorno, y de la propia organización, a la consecución no ya de los intereses mutuos, sino de aquellos intereses encaminados al bienestar y la felicidad, insistimos, eudaimónica. Que ganen las dos partes, de acuerdo, pero en términos eudaimónicos y no tanto materiales. Es decir, amén de cumplir con sus objetivos concreto de comunicación, habrán de ser unas Relaciones Públicas dirigidas a fortalecer la felicidad virtuosa tanto de la empresa u organización como la de sus públicos, un planteamiento que entronca de lleno con lo que algunos llaman la Organizational Virtuousness (Cameron et al., 2004).

\subsection{Organizational Virtuousness, más allá de la RSC}

También a la hora de hablar de la felicidad en el seno de una organización, de una empresa, se puede, y se debe, adoptar la perspectiva eudaimónica. Como ponen de manifiesto, entre otros, Rego et al. (2011), ciertamente cabe la posibilidad de que la felicidad pudiera estar interactuando con la virtud empresarial en pro del éxito y el nivel de desempeño organizacional. Es decir, parece que cultivar una felicidad neta desde lo que podríamos llamar eudaimonia empresarial, es algo saludablemente exitoso. En esa línea, Cameron et al. (2004) propusieron un modelo propio de cinco factores con el que describir la relación entre el desempeño y lo que ellos mismos denominaron Organizational Virtuousness (OV):

Optimismo Organizacional: cuando bajo un sentido profundo que guía las acciones de los miembros de una organización, éstos esperan mayoritariamente tener éxito incluso en aquellos retos más difíciles.

Perdón Organizacional: lo cual significa que aquellos errores cometidos desde la honestidad son recibidos por parte de la organización con misericordia, y son considerados, al mismo tiempo, como una oportunidad para el aprendizaje. 
Confianza Organizacional: cuando cortesía, consideración, y respeto gobiernan la organización, haciendo que sus miembros confíen los unos en los otros. En definitiva, la primacía de la confianza frente al control, contradiciendo aquella triste frase de Lenin de que "la confianza es buena, pero el control es mejor", ya que, en palabras de Sonnenfeld "sin confianza, el control ni siquiera es eficiente" (2010, p. 58).

Compasión Organizacional: los miembros de algún modo cuidan unos de otros, siendo común la simpatía, y más aún, la empatía, al compartirse las preocupaciones e inquietudes de una manera generalizada y constructiva.

Integridad Organizacional: honestidad, integridad y honor impregnan la organización en cuanto a valores supremos de la cultura de la misma, y es así percibido por las personas que la componen.

Seguidamente, estos mismos autores encontraron relación entre esta Organizational Virtuousness (OV) percibida por los miembros de una organización, y el desempeño organizacional, todo ello mediado por valores significativamente positivos de bienestar y felicidad. Dicha virtud organizacional percibida, como no puede ser de otro modo, tendrá no obstante como línea de partida el escrupuloso respeto de los Derechos Humanos, y no solo por parte de la empresa o la organización misma, sino el compromiso de que solo se hará tratos, ya sea como cliente, proveedor o colaborador de cualquier clase, con agentes que cumplan también con los mismos, algo que entronca con el paradigma de la Responsabilidad Social Corporativa, superándolo incluso en algún sentido. Pero no se trata ya de acompañar la labor principal de la compañía con acciones socialmente responsables, y que desde el punto de vista de la comunicación se puedan aprovechar para la mejora de la imagen y el compromiso mutuo entre sociedad y empresa, sino de tener una verdadera vocación de servicio en pro de la felicidad de públicos tanto internos como externos. Siendo así, la felicidad será la clave del éxito empresarial en términos globales.

Parece, por tanto, fundamental para una empresa hacer confluir no ya el discurso con las acciones, sino con la realidad misma de la empresa. Es decir, la comunicación de una empresa se sustenta cada vez menos en lo que dice, y más en la que hace. Del decir se pasa al hacer, y de ahí, como paso subsiguiente, al ser, esto es, a que la esencia y la misión de la empresa sea realmente la felicidad y la virtud, replanteándose seriamente su propia naturaleza. Hablando de personas Zak dirá que "la única forma de hacer que sea creíble durante mucho tiempo la impresión de ser una persona de fiar, es ser una persona de fiar" (2012, p. 43). Exactamente lo mismo cabe decir de una empresa o una marca. Si esto ha debido ser así siempre, piénsese lo perentorio que resulta en un escenario como el actual, con el auge de la comunicación digital y los medios sociales. Habrá que empezar por preguntarnos ¿para qué están aquí realmente las empresas, para qué nos hemos dado los seres humanos tales instituciones? Y una vez que sepamos la respuesta, poner la comunicación al servicio de la misma.

\section{CONCLUSIÓN}

La Asamblea General de las Naciones Unidas, en junio de 2012, declaró oficialmente

“...que la felicidad y el bienestar guíen los objetivos de las políticas públicas de los 
países." Cabría decir que, más que de un salto hacia delante, estemos dándolo hacia otra dirección distinta, pues si a principios del siglo XIX se hacía bandera de una felicidad cercana al concepto de riqueza, en la actualidad el camino va en sentido contrario. Si la ONU hoy se ve obligada a poner el acento en la felicidad y el bienestar de las personas, lo hace en contraposición precisamente, o al menos al margen, de la riqueza, del crecimiento material y económico que per se ha marcado el afán de vida de personas y países durante tantos decenios. Determinados parámetros económicos y materiales se han vuelto desde hace ya demasiado tiempo un fin en sí mismos, fin para el que los seres humanos se convirtieron en un medio, en unos "recursos" humanos como otros cualesquiera. Tal vez sea el momento de volver a poner a las personas en el sitio del fin último, y no en el apartado "recursos".

Es de esperar que esa resolución de la ONU tenga consecuencias en las políticas de los países, y también en el resto de organizaciones, entre las que se encuentran con gran protagonismo las empresas y corporaciones, y se ponga el norte en lo que de verdad importa. En ese sentido, cada vez son más numerosas las evidencias científicas que se suman a las que ya existían intuitivamente de que no parece que la abundancia material traiga sin género de dudas la felicidad de las personas (Kasser y Sheldon, 2009). Por tanto, ya sea a nivel estatal como empresarial, tal vez esté llegando la hora, acuciados los tiempos por el colapso de buena parte del sistema económico y financiero actual, de un cierto cambio de enfoque, un cambio en el principio rector de la actividad económica que no sea el dinero, como señalara Kahneman (2006). Sonnenfeld apuntará en esta dirección al señalar que "no es lo mismo prestar un servicio auténtico que permita ganar dinero que querer por encima de todo ganar dinero prestando para ello un determinado servicio" (2010, p. 75).

Tal vez sea cierto eso de que estemos entrando, en una "economía de satisfacción con la vida -con respecto y por encima del dinero- y que, para que un negocio prospere, debe cultivar las relaciones y tener sentido" (Seligman, 2011, p. 94). En el mismo sentido, el ya mencionado Sonnenfeld dirá que "No hay duda de que ganar dinero es condición imprescindible para el buen funcionamiento de una empresa de negocios, pero no es una condición suficiente" (2010, p. 110). Sea o no así, la apuesta es hacer de la empresa una fuente no tanto de riqueza como de felicidad, hacer de toda organización, con o sin ánimo de lucro, un ente que se instale en esa nueva perspectiva del Positive-People-Management (PPM), en palabras de Rego et al. (2011), esto es, en una verdadera filosofía empresarial positiva y fundamentada por y para el servicio, el bienestar y la felicidad de las personas, las que están dentro y fuera de las empresas y las organizaciones.

La felicidad, hemos visto, es fruto de la comunicación, la interpersonal y la mediada, pero también la que emana de las empresas y las organizaciones. Si la misión de las empresas, hemos dicho que es hacer feliz a las personas, la misión de toda comunicación deberá ser, por tanto, la misma. Tal vez parezca algo optimista, pero es la visión que defendemos de la evolución humana, como la que sostiene Ridley (2011), quien afirma que el progreso humano ha sido sustentado por el intercambio basado en el principio de confianza mutua, de interdependencia y de cooperación, algo que comparte con Zak (2012) y otros neuroeconomistas. En cualquier caso, bienvenido sea dicho optimismo, pues creemos en las palabras de Carmelo Vázquez (en Avia y 
Vázquez, 2011), cuando afirma que el optimismo es hoy y ante todo una exigencia ética, para con nosotros mismos, y para con los demás.

\section{REFERENCIAS BIBLIOGRÁFICAS}

Achor, S. (2011). La felicidad como ventaja. Los 7 principios de la psicología positiva para alcanzar el éxito. Barcelona: RBA.

Avia, M.D. y Vázquez, C. (2011). Optimismo Inteligente (2a ed.). Madrid: Alianza.

Barbuto, J. E., Jr., \& Wheeler, D. W. (2006). Scale development and construct clarification of servant leadership. Group E Organization Management, 31(3), 300-326.

Botton, A. (2004). Ansiedad por el estatus. Madrid: Taurus.

Buijzen, M. y Valkenburg, P.M. (2003). The effects of television advertising on materialism, parent-child conflict, and unhappiness: A review of research. Journal of Applied Developmental Psychology, vol. 24, 4, 437-456.

Cameron, K.S. Bright, D. y Caza, A. (2004). Exploring the relationships between organizational virtuousness and performance. American Behavioral Scientist, 47 (6), 124.

Carretero Bermejo, R. (2010). Resiliencia. Una visión positiva para la prevención e intervención desde los servicios sociales. Nómadas, 27. Encontrado en http:/ / redalyc.uaemex.mx/ src/inicio/ ArtPdfRed.jsp?iCve=18113757004, 2012).

Chiumento (2007). Happiness at Work Index Research report. Encontrado en http:/ / www.arboraglobal.com/documents/Happiness $\% 20$ at $\%$ 20Work $\% 20$ Index $\% 202$ 007.pdf, (12-10-2011).

Cohen, S., Doyle, W. T., Turner, R. B., Alper, C. M. y Skoner, D. P. (2003): Emotional style and susceptibility to the common cold, Psychosomatic Medicine, 65, 652-657.

Csikszentmihalyi, M. (1996). Fluir (Flow). Una psicología de la felicidad. Barcelona: Kairós.

Dolan, P. y Metcalfe, R. (2012) The relationship between innovation and subjective wellbeing. Research Policy, vol. 41, 8, 1489-1498.

Eguizábal, R. (2007). Teoría de la publicidad. Madrid: Cátedra.

Fisher, C. D. (2010), Happiness at Work. International Journal of Management Reviews, 12, 384-412.

Gancedo, M. (2006). Virtudes y fortalezas: el revés de la trama. Psicodebate, 7, 67-80. 
Comunicación positiva - Persuasión positiva - Publicidad positiva - Responsabilidad Social Empresarial (RSE) - Felicidad - Bienestar psicológico

Greenleaf, R. K. (1977). Servant-leadership: A journey into the nature of legitimate power and greatness. Mahwah, NJ: Paulist Press.

Hackett, R.D. y Wang, G. (2012). Virtues and leadership an integrating conceptual framework founded in Aristotelian and Confucian perspectives on virtues.

Management Decision, vol. 50, 5, 68-899.

Kahneman D., Krueger A.B., Schkade D., et al. (2006). Would you be happier if you were richer? A focusing illusion. Science, 312, 1908-1910.

Kasser, T. y Sheldon, K. M. (2009). Time affluence as a path toward personal happiness and ethical business practice: empirical evidence from four studies. Journal of Business Ethics, 84, 243-255.

Linden, R. C., Wayne, S. J., Zhao, H., \& Henderson, D. (2008). Servant leadership: Development of a multidimensional measure and multi-level assessment. The Leadership Quarterly, 19, 161-177.

Lyubomirsky, S., King, L. y Diener, E. (2005). The benefits of frequent positive affect: Does happiness lead to success? Psychological Bulletin, 131 (6), 803-855.

Lyubomirsky, S. (2011). La ciencia de la felicidad. Barcelona: Books4pocket.

Magallón, S. (2006). Concepto y elementos de las relaciones públicas. Anàlisi, 34, 103109.

Mithen, S. J. (2006). The Singing Neanderthals. The Origins of Music, Language, Mind, and Body. Cambridge: Harvard University Press.

Mora, F. (2012). ¿Está nuestro cerebro diseñado para la felicidad? Madrid: Alianza.

Padrós, F., Martínez, M.P., Gutiérrez-Hernández, C. Y. y Medina, M.A. (2010). La psicología positiva. Una joven disciplina científica que tiene como objeto de estudio un viejo tema, la felicidad. En Uaricha, Revista de Psicología 14, 30-40.

Peterson, C. y Seligman, M. E. P. (2004). Character Strengths and Virtues. A handbook and classification. APA \& Oxford University Press.

Rego, A., Ribeiro, N., Pina, M. y Correia Jesuino, J. (2011). How happiness mediates the organizational virtuousness and affective commitment relationship. Journal of Business Research, 64, 524-532.

Richins, M.L. (1995). Social-comparison, advertising, and consumer discontent, American Behavioral Scientist, vol. 38, 4, 593-607.

Ridley, M. (2011). El optimista racional. Madrid: Taurus.

Robinson, K. (2009). El elemento. Descubrir tu pasión lo cambia todo. Barcelona: Grijalbo. 
Romero, M. y Sánchez, M. (2012). Análisis del uso del impacto emocional y la felicidad como recursos publicitarios en tiempos de crisis, en el II Congreso Publiradio, Universidad Autónoma de Barcelona, mayo.

Russell, B. (1978). La conquista de la felicidad. Madrid: Espasa-Calpe.

Ryan, R. M. y Deci, E. L. (2001). On Happiness and Human Potentials: A Review of Research on Hedonic and Eudaimonic Well-Being. Annuary Reveiw of Psychology, 52, 141-166.

Seligman, M. E. P. (2004). Aprenda optimismo. Barcelona: Debolsillo.

Seligman, M.E.P. (2011). La vida que florece. Barcelona: Ediciones B.

Sharma, R. (2010). El líder que no tenía cargo. Barcelona: Random House Mondadori.

Stafford, L. D., Ng, W., Moore, R.A. y Bard, K. A. (2010). Bolder, happier, smarter: The role of extraversion in positive mood and cognition. Personality and individual differences, vol. 48, 7, 827-832.

Tolle, E. (2009). El Poder Del Ahora: Un Camino Hacia La Realización Espiritual. Madrid: Gaia.

Ulrich, D. y Ulrich, W. (2011). EL sentido de trabajar. Madrid: LID.

Van Dierendonck, D. y Nuijten, I. (2010). The Servant Leadership Survey: development and validation of a multidimensional measure. Journal of Business and Psychology, 26(3), 249-267.

Watzlawick, P. (1993). Teoría de la comunicación humana. Barcelona: Herder.

Wilcox, d. L., Cameron, G. T. y Xifra, J. (2006). Relaciones Públicas. Estrategias y tácticas. Madrid: Pearson.

Zak, P.J. (2012). La molécula de la felicidad. El origen del amor, la confianza y la prosperidad. Barcelona: Indicios.

\section{José Antonio Muñiz Velázquez}

Profesor de Comunicación en la Universidad Loyola Andalucía. Doctor en Comunicación por la Universidad de Sevilla, Master Europeo en Marketing Relacional, Directo e Interactivo por ICEMD-ESIC Business School, Licenciado en Publicidad y Relaciones Públicas por la Universidad de Sevilla, y Licenciado en Psicología por la U.N.E.D. Además, ha realizado diferentes postgrados en el ámbito de la Comunicación, la Psicología y el Coaching. Con casi 10 años de experiencia docente, ha sido profesor en universidades como la Pontificia de Salamanca, la Universidad de Sevilla, la IULM (Milán), la Università di Macerata, o la Universidad San Jorge de 
Zaragoza, donde además ha sido investigador principal del Felicicom Lab, grupo de investigación en Comunicación Organizacional, Persuasión y Felicidad. En la actualidad, sigue siendo profesor invitado en diferentes postgrados en varias de dichas universidades, así como profesor y formador en el entorno empresarial en el ámbito de la comunicación, el liderazgo y la felicidad.

\section{Alejandro Ávarez Nobell}

Licenciado en Comunicación Social por la Universidad Nacional de Córdoba (Argentina), doctorando en Dirección Estratégica de la Comunicación y Máster en Gestión Estratégica e Innovación en Comunicación por la Universidad de Málaga. Ha trabajado en INFOXEL Inteligencia en Medios como director de operaciones y asesor senior en análisis de medios, $\mathrm{AD}$, mediasponsoring e imagen mediática para marcas de primera línea, y como consultor en Comunicación, Imagen e Identidad Mediática. Actualmente, es editor de la revista académica Pangea (RAIC), investigador del grupo de investigación Felicicom Lab, profesor de grado y posgrado, y director del Máster Universitario en Marketing y Comunicación Corporativa de la Universidad San Jorge. 


\section{ANEXO: LAS 6 VIRTUDES Y 24 FORTALEZAS DEL SER HUMANO (Peterson y Seligman, 2004)}

\section{Sabiduría y conocimiento}

Fortalezas cognitivas que implican la adquisición y el uso del conocimiento.

1. Curiosidad, interés por el mundo

Tener interés por lo que sucede en el mundo, encontrar temas fascinantes, explorar y descubrir nuevas cosas.

\section{Amor por el conocimiento y el aprendizaje}

Llegar a dominar nuevas materias y conocimientos, tendencia continua a adquirir nuevos aprendizajes.

\section{Juicio, pensamiento crítico, mentalidad abierta}

Pensar sobre las cosas y examinar todos sus significados y matices. No sacar conclusiones al azar, sino tras evaluar cada posibilidad. Estar dispuesto a cambiar las propias ideas en base a la evidencia.

\section{Ingenio, originalidad, inteligencia práctica}

Pensar en nuevos y productivos caminos y formas de hacer las cosas. Incluye la creación artística pero no se limita exclusivamente a ella.

\section{Perspectiva}

Ser capaz de dar consejos sabios y adecuados a los demás, encontrando caminos no sólo para comprender el mundo sino para ayudar a comprenderlo a los demás.

\section{Coraje}

Fortalezas emocionales que implican la consecución de metas ante situaciones de dificultad, externa o interna.

\section{Valentía}

No dejarse intimidar ante la amenaza, el cambio, la dificultad o el dolor. Ser capaz de defender una postura que uno cree correcta aunque exista una fuerte oposición por parte de los demás, actuar según las propias convicciones aunque eso suponga ser criticado. Incluye la fuerza física pero no se limita a eso.

\section{Perseverancia y diligencia}

Terminar lo que uno empieza. Persistir en una actividad aunque existan obstáculos. Obtener satisfacción por las tareas emprendidas y que consiguen finalizarse con éxito.

\section{Integridad, honestidad, autenticidad}

Ir siempre con la verdad por delante, no ser pretencioso y asumir la responsabilidad de los propios sentimientos y acciones emprendidas.

\section{Vitalidad y pasión por las cosas}

Afrontar la vida con entusiasmo y energía. Hacer las cosas con convicción y dando todo de uno mismo. Vivir
Iusticia

Fortalezas cívicas que conllevan una vida en comunidad saludable.

\section{Ciudadanía, civismo, lealtad, trabajo en equipo}

Trabajar bien dentro de un equipo o grupo de personas, ser fiel al grupo y sentirse parte de él.

\section{Sentido de la justicia, equidad}

Tratar a todas las personas como iguales en consonancia con las nociones de equidad y justicia. No dejar que los sentimientos personales influyan en decisiones sobre los otros, dando a todo el mundo las mismas oportunidades.

\section{Liderazgo}

Animar al grupo del que uno es miembro para hacer cosas, así como reforzar las relaciones entre las personas de dicho grupo. Organizar actividades grupales y llevarlas a buen término.

\section{Moderación}

Fortalezas que nos protegen contra los excesos.

16. Capacidad de perdonar, misericordia

Capacidad de perdonar a aquellas personas que han actuado mal, dándoles una segunda oportunidad, no siendo vengativo ni rencoroso.

\section{Modestia, humildad}

Dejar que sean los demás los que hablen de uno mismo, no buscar ser el centro de atención y no creerse más especial que los demás.

18. Prudencia, discreción, cautela

Ser cauteloso a la hora de tomar decisiones, no asumiendo riesgos innecesarios ni diciendo o haciendo nada de lo que después uno se pueda arrepentir.

\section{Auto-control, auto-regulación}

Tener capacidad para regular los propios sentimientos y acciones. Tener disciplina y control sobre los impulsos y emociones. 


\section{Comunicación positiva - Persuasión positiva - Publicidad positiva - Responsabilidad Social Empresarial (RSE) - Felicidad - Bienestar psicológico}

\begin{tabular}{|c|c|}
\hline $\begin{array}{l}\text { la vida como una apasionante aventura, sintiéndose } \\
\text { vivo y activo. }\end{array}$ & \\
\hline Humanidad & Trascendencia \\
\hline $\begin{array}{l}\text { Fortalezas interpersonales que implican cuidar y ofrecer } \\
\text { amistad y cariño a los demás. }\end{array}$ & $\begin{array}{l}\text { Fortalezas que forjan conexiones con la inmensidad del } \\
\text { universo y proveen de significado la vida. }\end{array}$ \\
\hline 10. Amor, apego, capacidad de amar y ser amado & $\begin{array}{l}\text { 20. Apreciación de la belleza y la excelencia, capacidad de } \\
\text { asombro }\end{array}$ \\
\hline $\begin{array}{l}\text { Tener importantes y valiosas relaciones con otras } \\
\text { personas, en particular con aquellas en las que el afecto } \\
\text { y el cuidado son mutuos. Sentirse cerca y apegado a } \\
\text { otras personas. }\end{array}$ & $\begin{array}{l}\text { Saber apreciar la belleza de las cosas, del día a día, o } \\
\text { interesarse por aspectos de la vida como la naturaleza, el } \\
\text { arte, la ciencia... }\end{array}$ \\
\hline 11. Simpatía, amabilidad, generosidad & 21. Gratitud \\
\hline $\begin{array}{l}\text { Hacer favores y buenas acciones para los demás, ayudar } \\
\text { y cuidar a otras personas. }\end{array}$ & $\begin{array}{l}\text { Ser consciente y agradecer las cosas buenas que a uno le } \\
\text { pasan. Saber dar las gracias. }\end{array}$ \\
\hline 12. Inteligencia emocional, personal y social & 22. Esperanza, optimismo, proyección hacia el futuro \\
\hline $\begin{array}{l}\text { Ser consciente de las emociones y sentimientos tanto de } \\
\text { uno mismo como de los demás, saber cómo comportarse } \\
\text { en las diferentes situaciones sociales, saber }\end{array}$ & $\begin{array}{l}\text { Esperar lo mejor para el futuro y trabajar para conseguirlo. } \\
\text { Creer que un buen futuro es algo que está en nuestras manos } \\
\text { conseguir. } \\
\text { 23. Sentido del humor } \\
\text { Gustar de reír y gastar bromas, sonreír con frecuencia, ver el } \\
\text { lado positivo de la vida. } \\
\text { 24. Espiritualidad, fe, sentido religioso } \\
\text { Pensar que existe un propósito o un significado universal en } \\
\text { las cosas que ocurren en el mundo y en la propia existencia. } \\
\text { Creer que existe algo superior que da forma y determina } \\
\text { nuestra conducta y nos protege. }\end{array}$ \\
\hline
\end{tabular}

